\title{
Microstructure and Mechanical Behavior of FeNiCoCr and FeNiCoCrMn High-Entropy Alloys Fabricated by Powder Metallurgy
}

\author{
Chenliang Chu ${ }^{1} \cdot$ Weiping Chen ${ }^{1} \cdot$ Zhen Chen $^{1,2} \cdot$ Zhenfei Jiang $^{1} \cdot$ Hao Wang ${ }^{1} \cdot$ Zhiqiang Fu $^{1}$
}

Received: 9 June 2020 / Revised: 5 August 2020 / Accepted: 14 August 2020 / Published online: 15 October 2020

(C) The Chinese Society for Metals (CSM) and Springer-Verlag GmbH Germany, part of Springer Nature 2020

\begin{abstract}
The present work reports a systematic investigation on phase evolution, microstructure and microstructure-property relationship of two typical face-centered cubic (FCC) structured high-entropy alloys (HEAs), FeNiCoCr and FeNiCoCrMn, prepared via mechanical alloying (MA) followed by spark plasma sintering (SPS). Following $50 \mathrm{~h}$ of MA, the two HEAs consisted of a mixture of FCC and body-centered cubic phases. Following SPS, the bulk FeNiCoCr alloy showed a primary FCC phase with a small amount of $\mathrm{Cr}_{23} \mathrm{C}_{6}$ and $\mathrm{Cr}_{2} \mathrm{O}_{3}$ contaminants, while the bulk FeNiCoCrMn alloy was composed of a primary FCC phase with some $(\mathrm{Cr}, \mathrm{Mn})_{23} \mathrm{C}_{6}$ and $\mathrm{MnCr}_{2} \mathrm{O}_{4}$ contaminants. The average grain size of the primary FCC phase in the bulk FeNiCoCr alloy was $\sim 416 \mathrm{~nm}$, while that of the primary FCC phase in the bulk FeNiCoCrMn alloy was $\sim 547 \mathrm{~nm}$. The yield strength, compressive strength and strain-to-failure of the bulk FeNiCoCr alloy are $1525 \mathrm{MPa}, 1987 \mathrm{MPa}$ and $24.4 \%$, respectively, whereas those of the bulk FeNiCoCrMn alloy are $1329 \mathrm{MPa}, 1761 \mathrm{MPa}$ and $21.9 \%$, respectively. It suggests that the bulk FeNiCoCrMn exhibited lower strength and plasticity in comparison with the bulk FeNiCoCr alloy. Clearly, the smaller grain size of the primary FCC phase in the FeNiCoCr alloy is mainly responsible for the better mechanical performance.
\end{abstract}

Keywords High-entropy alloy $\cdot$ Mechanical alloying $\cdot$ Microstructure $\cdot$ Strengthening $\cdot$ Contaminants

\section{Introduction}

With the number of alloying elements increases, intermetallic compounds (IMCs) or other complicated phases are likely to form in conventional alloy systems, resulting in complex microstructures and disappointing mechanical properties. A novel kind of alloys, high-entropy alloys (HEAs), proposed by Yeh et al. in 2004 have broken through the traditional alloy design strategy [1]. Up-to-date, HEAs are usually regarded as multi-principal element alloys displaying at least four principal elements with 5-35 at.\% concentrations for each element [2]. In light of multi-principal element compositions, HEAs show notably higher configurational entropy than conventional alloys with one or two principal elements,

Available online at http://link.springer.com/journal/40195.

Zhiqiang $\mathrm{Fu}$

zhiqiangfu2019@scut.edu.cn; kopyhit@163.com

$1 \quad$ Guangdong Key Laboratory for Advanced Metallic Materials Processing, South China University of Technology, Guangzhou 510640, China

2 Shantou Technician College, Shantou 515041, China referring to high entropy effect. It has been proposed that the high entropy effect of HEAs tends to suppress the formation of IMCs, thereby allowing them to form solid solutions with simple face-centered cubic (FCC) and/or body-centered cubic (BCC) and/or hexagonal closest packed (HCP) structures [3-5]. HEAs have exhibited appealing structural and functional properties, such as high hardness and strength [6], superior resistance to creep [7], excellent oxidation resistance [8], outstanding irradiation resistance [9], high ballistic resistance [10] and unique magnetic properties [11]. Accordingly, HEAs show great promise in a number of engineering applications, and they have triggered remarkable research interest from the materials community in the past decade.

Among various HEAs' systems, the most deeply studied HEAs are designed based on III-rd to XII-th's transition metals, such as the well-known "Cantor alloy" (equiatomic FeNiCoCrMn HEA) and its derivative alloys (e.g., equiatomic FeNiCoCr HEA) [12, 13]. Inspection of the HEA literature reveals that equiatomic $\mathrm{FeNiCoCrMn}$ HEA with a single FCC structure could be stabilized at temperatures $>900{ }^{\circ} \mathrm{C}$ [14]. In addition to the high thermal stability, this HEA possesses desirable ductility and high fracture toughness at room temperature and ultralow 
temperatures $[15,16]$. Therefore, equiatomic FeNiCoCrMn HEA has been studied by many researchers and more recently there has been increasing interest in the derivative alloys of this HEA by tailoring alloying elements. Albeit with outstanding ductility, FCC-structured FeNiCoCrMn HEA and its derivative alloys fabricated by melting and casting suffer relatively low yield strength $(\leq 215 \mathrm{MPa})$ at room temperature [17].

Recently, a promising powder metallurgy (P/M) technology, the combination of mechanical alloying (MA) and spark plasma sintering (SPS), has been used to fabricate HEAs with the aim to address drawbacks of conventional melting and casting. It is well known that MA is an advanced method of fabricating nonequilibrium nano- and/or ultrafine-grained (NG/UFG) alloys with homogeneous chemical compositions and microstructures $[18,19]$. Compared with traditional sintering methods, the spark plasma sintering (SPS) is a promising technique for producing dense bulk materials with high performance via applying load and passing electric pulse current in a short duration [20]. In addition, SPS can rapidly consolidate HEA powders into NG and/or UFG bulk samples. Therefore, HEAs prepared via MA followed by SPS possess exceptional high strength [21]. It suggests that the strength of FCC-structured FeNiCoCrMn HEA and its derivative alloys could be enhanced using the combination of MA and SPS.

Nevertheless, it is worth noting that carbide and oxide contaminants are inevitably formed in HEAs fabricated by the combination of MA and SPS. However, such carbide and oxide contaminants are usually overlooked by researchers on account of trace amounts. To the best of our knowledge, only a few studies have mentioned these kinds of contaminants. Sathiyamoorthi et al. [22] found that the source of carbon in FeNiCoCr HEA synthesized by MA and SPS was the process control agent (PCA) used in the milling process. Additionally, Vaidya et al. [23] observed the formation of $\mathrm{Cr}$-carbides in $\mathrm{FeNiCoCr}$ and $\mathrm{FeNiCoCrMn} \mathrm{HEAs} \mathrm{with}$ prolonged wet milling duration, suggesting that the carbon originated from the decomposition of PCA. However, these studies focused on the investigation of thermal stability or grain growth of HEAs. The influence of carbide and oxide contaminants on microstructure and mechanical behavior of $\mathrm{FeNiCoCr}$ and $\mathrm{FeNiCoCrMn} \mathrm{HEAs} \mathrm{prepared} \mathrm{by} \mathrm{MA} \mathrm{and}$ SPS remains poorly understood.

Motivated by the above discussion, we aimed to enhance the strength of equiatomic FeNiCoCrMn and its derivative alloy $\mathrm{FeNiCoCr}$ HEA by introducing NG or UFG microstructure in this work. To that effect, the combination of MA and SPS was used to prepare these two HEAs. Phase evolution, microstructure and microstructure-property relationship were discussed in detail. In particular, the influence of carbide and oxide contaminants on the microstructure and mechanical behavior was systematically investigated.

\section{Experimental}

Equiatomic $\mathrm{FeNiCoCr}$ and $\mathrm{FeNiCoCrMn} \mathrm{HEAs} \mathrm{were} \mathrm{pre-}$ pared from pure elements via mechanical alloying (MA) followed by spark plasma sintering (SPS). Elemental powders of $\mathrm{Fe}, \mathrm{Ni}, \mathrm{Co}, \mathrm{Cr}$ and $\mathrm{Mn}$ with high purity ( $>99.7 \%$ in $\mathrm{wt} \%)$ and small particle size $(<45 \mu \mathrm{m})$ were initially blended for $5 \mathrm{~h}$. Subsequently, the blended powders were conducted by $45 \mathrm{~h}$ of dry milling and then $5 \mathrm{~h}$ of wet milling in ethanol (process control agent) to obtain the mechanically alloyed powders of $\mathrm{FeNiCoCr}$ and FeNiCoCrMn HEAs. The milling process was performed on a high energy planetary ball mill (QM-3SP4, Nanda Instrument Plant, China) at $300 \mathrm{rpm}$, using high-performance stainless steel vials and tungsten carbide balls (with a ball to powder ratio of 10:1) as the milling medium. After milling for $0,5,15,30,45$ and $50 \mathrm{~h}$, powder specimens were taken out, respectively, to study phase evolution during the process of MA. Following the wet milling, the milled powders were placed in a vacuum chamber to evaporate the ethanol at $60{ }^{\circ} \mathrm{C}$. Finally, the dried powders were compacted by spark plasma technique on a spark plasma sintering apparatus (Dr. Sinter SPS-825, Sumitomo Coal Mining Co. Ltd., Japan) at $1000{ }^{\circ} \mathrm{C}$ for a dwelling time of 8 min under vacuum (maintaining residual cell pressure $<10 \mathrm{~Pa}$ ) with applying a continuous uniaxial pressure of $30 \mathrm{MPa}$. Heating rates for room temperature to $100^{\circ} \mathrm{C}$, $100-1000{ }^{\circ} \mathrm{C}$ were 80 and $100{ }^{\circ} \mathrm{C}^{-1} \mathrm{~min}^{-1}$, respectively. For ensuring temperature homogeneities and extracting sintered bulks conveniently, graphite spacers with the thickness of $\sim 0.2 \mathrm{~mm}$ were ensconced between the powders and the punch. The bulk FeNiCoCr and FeNiCoCrMn HEAs samples with a geometry of $\Phi 20 \mathrm{~mm} \times \sim 10 \mathrm{~mm}$ were sectioned by wire cutting after cooled inside the furnace to room temperature for the subsequent testing.

Phase compositions of the milled powders and the bulk HEAs were determined by X-ray diffraction (XRD; D8

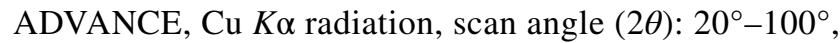
scan rate: $5 \mathrm{deg} . / \mathrm{min}$, scan step size: $0.02^{\circ}$ ). Specimens with geometry of $\Phi 10 \mathrm{~mm} \times \sim 0.5 \mathrm{~mm}$ for transmission electron microscopy (TEM) characterizations were cut from the bulk FeNiCoCr and FeNiCoCrMn samples using electrical discharge machining. The specimens were polished to approximately $40 \mu \mathrm{m}$ thick, and subsequently ground down to $\sim 25 \mu \mathrm{m}$ using dimpling followed by ion milling. The microstructure of the specimens was observed by a transmission electron microscope (200 kV TEM; TECNAI G2 S-TWIN F20, FEI, USA) equipped with attachments for selected area electron diffraction (SAED) and energy dispersive spectroscopy (EDS) analysis. Compression tests were carried out at room temperature using an Instron 5500 testing system at a strain rate of $1 \times 10^{-3}$ 
$\mathrm{s}^{-1}$. Three cylindrical compressive specimens with the size of $\Phi 3 \mathrm{~mm} \times 4.5 \mathrm{~mm}$ were tested for each sample. Vickers hardness of the specimens was measured by a digital micro hardness tester (HVS-1000) with $300 \mathrm{~g}$ load and $15 \mathrm{~s}$ dwell time before unloading. The data reported were the arithmetic average value from 10 different positions for each sample. In addition, the density of bulk $\mathrm{FeNiCoCr}$ and FeNiCoCrMn alloys was determined according to Archimedes' principle using high purity ethanol. More details on calculating the relative densities $(D)$ were described in our previous study [24].

\section{Results and Discussion}

\subsection{XRD Patterns of FeNiCoCr and FeNiCoCrMn HEAs}

Figure 1 presents the XRD patterns of $\mathrm{FeNiCoCr}$ and $\mathrm{FeN}$ iCoCrMn alloys. XRD patterns of the FeNiCoCr HEA powders and an SPS consolidated (at $1000{ }^{\circ} \mathrm{C}$ ) bulk sample are shown in Fig. 1a. Before the MA process $(0 \mathrm{~h})$, the diffraction peaks corresponding to all individual pure elements $(\mathrm{Fe}$, $\mathrm{Ni}, \mathrm{Co}$, and $\mathrm{Cr}$ ) can be clearly detected. After dry milling for $5 \mathrm{~h}$, the intensities of the diffraction peaks of all elements are remarkably weakened. As milling time increases to $15 \mathrm{~h}$, the intensities of the diffraction peaks of all elements show a further reduction. Following $30 \mathrm{~h}$ of dry milling, a small amount of $\mathrm{Fe}$ and $\mathrm{Cr}$ are still unalloyed. When the milling time is extended to $45 \mathrm{~h}$, the diffraction peaks of all elements are absent, indicating that alloying process has been completed. The alloying of $\mathrm{Fe}, \mathrm{Ni}, \mathrm{Co}$, and $\mathrm{Cr}$ elements leads to the formation of a primary FCC phase and a BCC phase. In order to obtain fine mechanically alloyed powders, an additional $5 \mathrm{~h}$ of wet milling was carried out using ethanol as PCA. Following $5 \mathrm{~h}$ of wet milling (i.e., $50 \mathrm{~h}$ of milling), the intensity of the diffraction peaks corresponding to the
FCC and BCC phases is evidently increased, and a slight peak broadening can also be observed. In the meantime, no newly formed phases can be detected after $5 \mathrm{~h}$ of wet milling. Following SPS, the peaks of the BCC phase disappear, whereas the peak intensity of the FCC phase is increased significantly suggesting that phase transformation and grain growth occurred during the SPS process. Note that the formation of a secondary phase indexed as an $M_{23} \mathrm{C}_{6}$ phase, can also be observed in the bulk $\mathrm{FeNiCoCr}$ alloy. However, the existence of $M_{23} \mathrm{C}_{6}$ peak is not evident due to the stacking of diffractograms in Fig. 1a. The mechanical alloying process of the FeNiCoCrMn alloy is similar to that of the $\mathrm{FeNiCoCr}$ alloy. Therefore, only the XRD pattern of the $50 \mathrm{~h}$ milled ( $45 \mathrm{~h}$ dry milling and $5 \mathrm{~h}$ wet milling) powders has been provided in Fig. $1 \mathrm{~b}$ along with the XRD pattern of an SPS consolidated (at $1000^{\circ} \mathrm{C}$ ) bulk sample for the $\mathrm{FeNiCoCrMn}$ HEA. After $50 \mathrm{~h}$ of milling, a primary FCC phase with the coexistence of BCC phase can be observed in the as-milled powders, while a primary FCC phase with a small amount of $M_{23} \mathrm{C}_{6}$ is present in the bulk $\mathrm{FeNiCoCrMn}$ alloy.

As mentioned above, both of the $\mathrm{FeNiCoCr}$ and FeNiCoCrMn alloys show a primary FCC phase with the coexistence of BCC phase after MA. Apparently, intermetallics or complex phases are absent in these two HEAs after MA, due to the fact that the constituent elements showing similar affinity result in a trend of 'mixing' (the so-called "highentropy effect") [25]. In addition, high strains and high dislocation density could be generated during the MA process, thereby leading to solid solubility extension [24]. As a result, the formation of supersaturated solid solutions with FCC and BCC structures occurred during the MA process. The broadening of diffraction peaks along with increased intensity suggests that the presence of crystallite refinement and an increment of lattice strain occurred in the $50 \mathrm{~h}$ as-milled $\mathrm{FeNiCoCr}$ and $\mathrm{FeNiCoCrMn} \mathrm{powders.} \mathrm{The} \mathrm{powders} \mathrm{suffer-}$ ing circulation of crushment and agglomeration during the
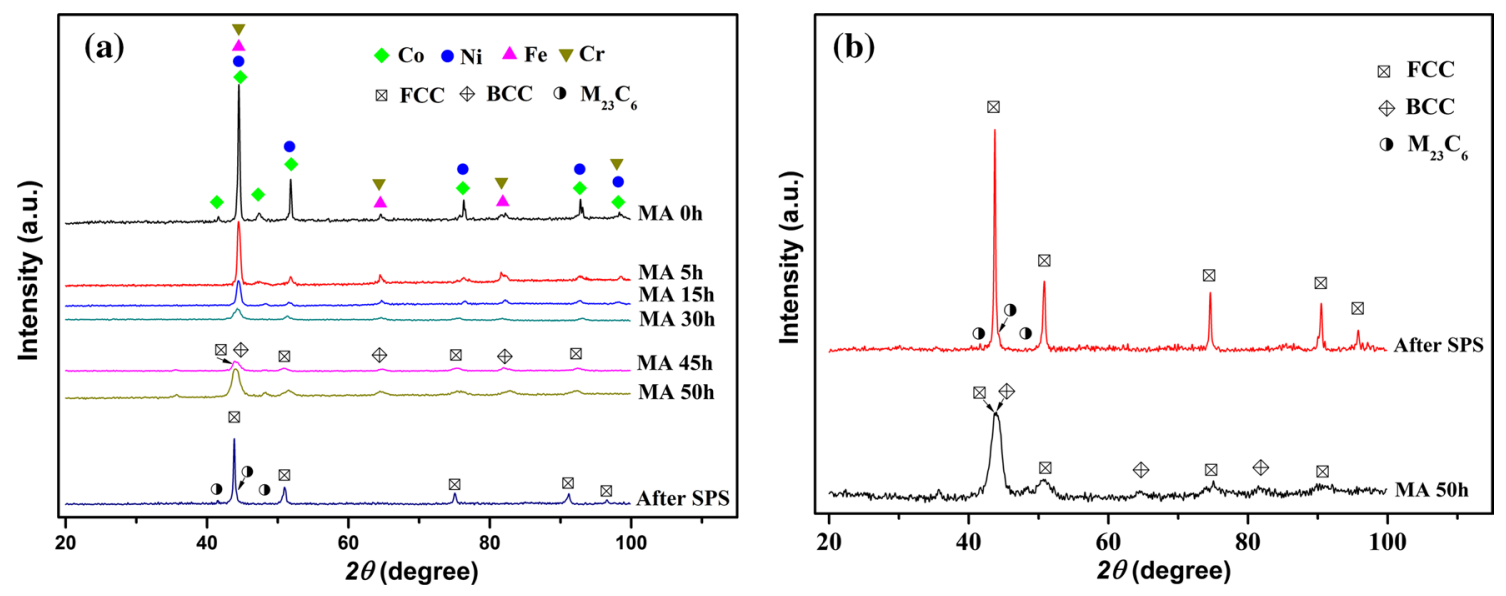

Fig. 1 XRD patterns of FeNiCoCr and FeNiCoCrMn HEAs: a FeNiCoCr, b FeNiCoCrMn 
MA process is mainly responsible for the crystallite refinement, while the booming of grain boundary and dislocation fraction imparted by MA results in the lattice strain [26].

During the MA process, Ni, Co and Mn favors the formation of FCC-structured solid-solution phase [27]. Note that the minor $\mathrm{BCC}$ phase in the $50 \mathrm{~h}$ as-milled powders is expected to be a $\mathrm{Cr}-\mathrm{Fe}$ solid-solution phase. $\mathrm{Cr}$ exhibiting BCC-structure has a higher melting point $\left(1907^{\circ} \mathrm{C}\right)$ among the constituent elements, thereby favoring the formation of BCC-structured solid-solution phase during the MA stage [27]. As a result, the $\mathrm{FeNiCoCr}$ and $\mathrm{FeNiCoCrMn}$ alloys, even under the solid solubility extension state of MA, still exhibit a coexistence of FCC and BCC phases. Following SPS at $1000{ }^{\circ} \mathrm{C}$, the nonequilibrium BCC phase in the $50 \mathrm{~h}$ as-milled powders transformed into more stable FCC phase under high temperature, which is in agreement with the published studies that the two HEAs usually exhibit a single FCC phase in the homogenized state $[13,23]$. Note that the secondary phase indexed as $M_{23} \mathrm{C}_{6}$ phase in the two bulk HEAs, will be further studied in hereinafter.

\subsection{Microstructure of Bulk FeNiCoCr and FeNiCoCrMn HEAs}

The calculated relative densities $(D)$ for the bulk $\mathrm{FeNiCoCr}$ and FeNiCoCrMn HEAs are $98.8 \%$ and $97.5 \%$, respectively, suggesting that the mechanically alloyed HEA powders can be compacted to dense bulk materials via SPS consolidation.

Figure 2 presents TEM images of the bulk FeNiCoCr alloy consolidated by SPS at $1000^{\circ} \mathrm{C}$. As shown in Fig. 2a,
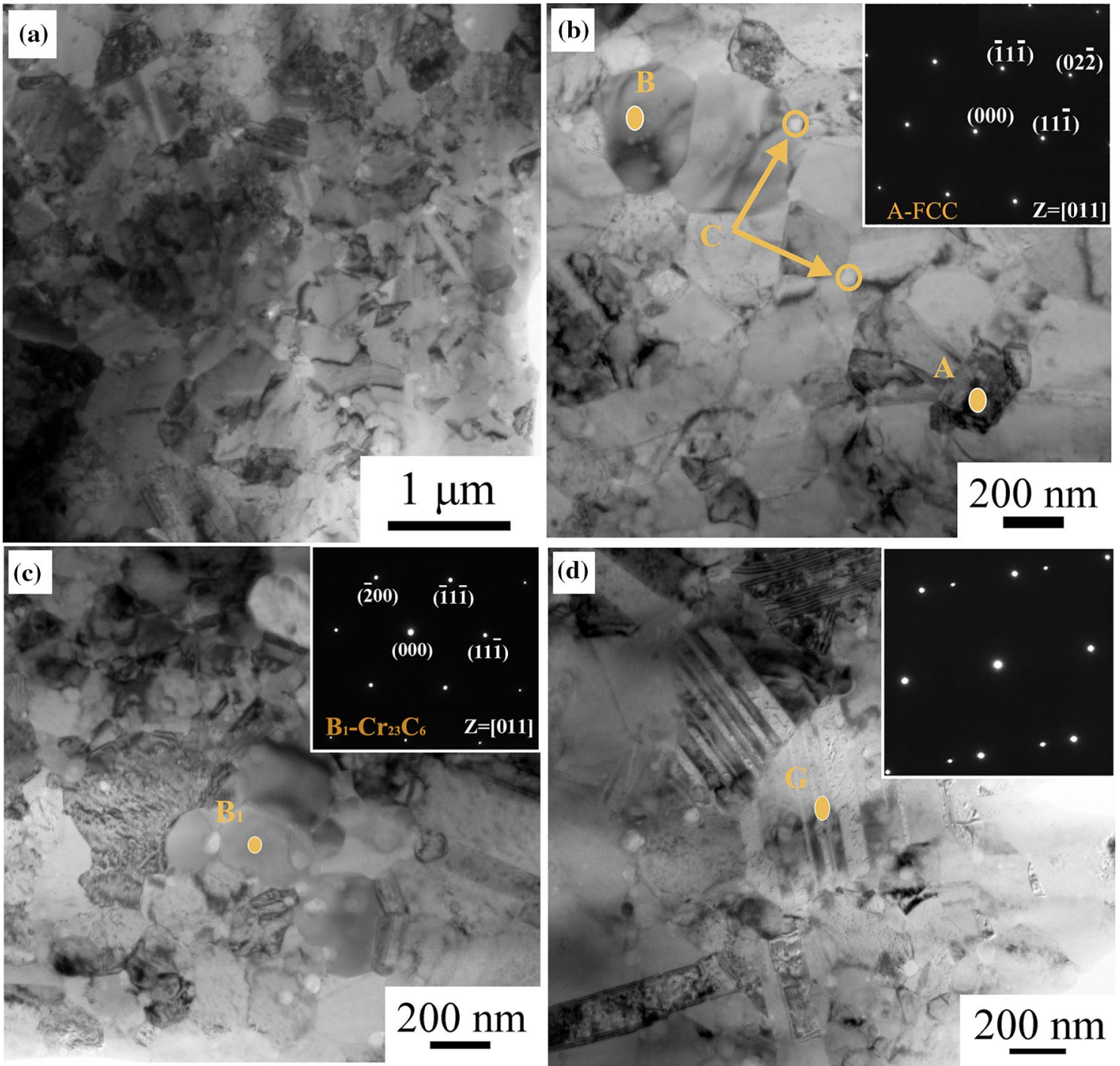

Fig. 2 Bright-field (BF) TEM images of bulk FeNiCoCr HEA: a low-magnified image; b high-magnified image and SAED pattern corresponding to grain $\mathrm{A}(\mathrm{FCC})$; $\mathbf{c}$ high-magnified image and SAED pattern corresponding to grain $\mathrm{B}_{1}\left(\mathrm{Cr}_{23} \mathrm{C}_{6}\right)$; $\mathbf{d}$ nanotwinned grain $\mathrm{G}$ and its corresponding SAED pattern 
bright-field (BF) images combining with EDS/TEM results suggest the presence of three distinctive types of phases in the bulk FeNiCoCr HEA, i.e., the primary FCC phase (A-type), Cr-rich carbide (B-type) and nanosized Cr-rich oxide (C-type). As shown in Fig. 2b, the SAED pattern corresponding to grain $\mathrm{A}$ in the upper right corner along the [011] zone axis shows a typical FCC structure. In addition, the EDS/TEM results listed in Table 1 are the average of five measurements. Note that the A-type phase with FCC structure is slightly Ni-Co-rich and Cr-depleted compared with the nominal composition of $\mathrm{FeNiCoCr}$ alloy. In addition, the average composition of the B-type phase is 58.4-65.6 at.\% in $\mathrm{Cr}$ and 16.2-21.4 at.\% in C, on the basis of the EDS/TEM results. Accordingly, these grains can be described as $\mathrm{Cr}_{23} \mathrm{C}_{6}$ phase, which is in accordance with the $M_{23} \mathrm{C}_{6}$ phase in the XRD analysis. To further identify B-type phase, the ZAll[011] pattern corresponding to grain $B_{1}$ is presented in Fig. 2c, suggesting that this kind of phase has an FCC structure with measured lattice parameters of $a=1.0632 \mathrm{~nm}$, which is nearly in accordance with $\mathrm{Cr}_{23} \mathrm{C}_{6}$ phase $(a=1.0659 \mathrm{~nm})$. The $\mathrm{Cr}_{23} \mathrm{C}_{6}$ carbide was also observed in $\mathrm{Al}_{0.3} \mathrm{CoCrFeNiC}_{0.1}$ HEA by Shun et al. [28] and $\mathrm{Al}_{0.5} \mathrm{CrFeNiCo}_{0.3} \mathrm{C}_{0.2} \mathrm{HEA}$ by Fang et al. [29]. Additionally, the EDS/TEM results show that the $\mathrm{Cr} / \mathrm{O}$ atomic ratio is about 0.6 in C-type nanosized phase, which is in relatively good agreement with the $\mathrm{Cr}_{2} \mathrm{O}_{3}$ phase. However, the presence of $\mathrm{Cr}$-rich oxide has not been identified by the XRD due to the small volume fraction and extremely small (nanoscale) grain size.

Figure 3 exhibits TEM images of the bulk FeNiCoCrMn alloy consolidated by SPS at $1000^{\circ} \mathrm{C}$. As shown in Fig. 3a, bright-field (BF) images combining with EDS/TEM results suggest there are also three distinctive types of phases in bulk FeNiCoCrMn HEA, i.e., the primary FCC phase (D-type), Cr-Mn-rich carbide (E-type) and nanosized $\mathrm{Cr}-\mathrm{Mn}$-rich oxide (F-type). As shown in Fig. 3b, the SAED pattern corresponding to grain $D$ taken from ZAll[011] shows a typical FCC structure. In addition, the EDS/TEM results show that the D-type phase with FCC structure is $\mathrm{Fe}-\mathrm{Ni}$-rich and $\mathrm{Cr}$-depleted compared with the nominal composition of equiatomic FeNiCoCrMn alloy. Meanwhile, the average composition of the E-type phase is 70.7-78.3 at.\% in Cr-Mn and 16.2-22.4 at.\% in C, on the basis of the EDS/TEM results. To further identify E-type phase, the ZAll[011] pattern corresponding to grain $\mathrm{E}_{1}$ is presented in Fig. 3c, suggesting that this kind of phase has an FCC structure with measured lattice parameters of $a=1.0711 \mathrm{~nm}$, which is nearly in accordance with $\mathrm{Cr}_{23} \mathrm{C}_{6}$ phase $(a=1.0659 \mathrm{~nm})$ with a small lattice expansion. Therefore, the E-type phase with a high concentration of Mn can be confirmed as $(\mathrm{Cr}, \mathrm{Mn})_{23} \mathrm{C}_{6}$ phase, which is in accordance with the $M_{23} \mathrm{C}_{6}$ phase in the XRD analysis. Moreover, the $\mathrm{Cr}_{2} \mathrm{O}_{3}$ phase in the $\mathrm{FeNiCoCr}$ alloy evolves to $\mathrm{MnCr}_{2} \mathrm{O}_{4}$ phase with the addition of $\mathrm{Mn}$ according to the EDS/TEM result in Table 1. The $\mathrm{MnCr}_{2} \mathrm{O}_{4}$ phase is also characterized based on TEM analysis by Pang et al. [30]. Thus, the bulk FeNiCoCr alloy shows a primary Cr-depleted FCC phase with a small amount of $\mathrm{Cr}_{23} \mathrm{C}_{6}$ phase and $\mathrm{Cr}_{2} \mathrm{O}_{3}$, while the bulk FeNiCoCrMn alloy is composed of a primary $\mathrm{Cr}$-depleted $\mathrm{FCC}$ phase with some $(\mathrm{Cr}, \mathrm{Mn})_{23} \mathrm{C}_{6}$ phase and $\mathrm{MnCr}_{2} \mathrm{O}_{4}$.

In addition, some nanoscale twins were observed in the bulk FeNiCoCr and FeNiCoCrMn HEAs. Figures $2 d$ and $3 \mathrm{~d}$ exhibit the TEM images and corresponding SAED patterns of nanoscale twins such as grain $\mathrm{G}$ in $\mathrm{FeNiCoCr}$ and grain $\mathrm{H}$ in FeNiCoCrMn. Apparently, in the bulk FeN$\mathrm{iCoCr}$ and $\mathrm{FeNiCoCrMn}$ alloys, the lamella thickness of nanoscale twins is less than $100 \mathrm{~nm}$. It is well know that the FCC phases with low SFE are inclined to yield twins [31, 32]. Moreover, Fu et al. [33] proposed that nanotwins could generate from severe plastic deformation by MA or phase evolution during SPS. Thus, it is not surprising that nanoscale twins could present in the $\mathrm{FeNiCoCr}$ and FeNiCoCrMn HEAs fabricated by the combination of MA and SPS.

Table 2 summarizes the values of mixing enthalpy $\left(\Delta H_{i j}^{\text {mix }}, \mathrm{kJ} \mathrm{mol}^{-1}\right)$ of different atom pairs calculated by Miedemas model [3, 34]. It can be seen that the difference of atomic radius among $\mathrm{Fe}, \mathrm{Ni}, \mathrm{Co}, \mathrm{Cr}$ and $\mathrm{Mn}$ is

Table 1 Chemical compositions (at.\%) of the bulk FeNiCoCr and FeNiCoCrMn HEAs analyzed by EDS/TEM

\begin{tabular}{|c|c|c|c|c|c|c|c|c|}
\hline Alloys & Regions & $\mathrm{Fe}$ & $\mathrm{Ni}$ & Co & $\mathrm{Cr}$ & $\mathrm{Mn}$ & $\mathrm{C}$ & $\mathrm{O}$ \\
\hline \multirow[t]{4}{*}{$\mathrm{FeNiCoCr}$} & Nominal composition & 25 & 25 & 25 & 25 & - & - & - \\
\hline & $\mathrm{FCC}(\mathrm{A})$ & $25.4 \pm 0.8$ & $27.0 \pm 1.1$ & $27.7 \pm 0.9$ & $19.9 \pm 0.8$ & - & - & - \\
\hline & Carbide phase (B) & $8.8 \pm 0.3$ & $4.5 \pm 1.3$ & $5.8 \pm 1.1$ & $62 \pm 3.6$ & - & $18.8 \pm 2.6$ & - \\
\hline & Oxide phase (C) & $2.1 \pm 1.1$ & $2.5 \pm 1.3$ & $2.6 \pm 1.5$ & $34.1 \pm 5.9$ & - & - & $58.7 \pm 4.8$ \\
\hline \multirow[t]{4}{*}{ FeNiCoCrMn } & Nominal composition & 20 & 20 & 20 & 20 & 20 & - & - \\
\hline & $\mathrm{FCC}(\mathrm{D})$ & $21.9 \pm 0.8$ & $21.0 \pm 1.1$ & $20.8 \pm 0.9$ & $16.2 \pm 1.1$ & $20.1 \pm 1.3$ & - & - \\
\hline & Carbide phase (E) & $3.2 \pm 0.2$ & $1.2 \pm 0.1$ & $1.8 \pm 0.1$ & $43.7 \pm 2.6$ & $30.8 \pm 1.2$ & $19.3 \pm 3.1$ & - \\
\hline & Oxide phase $(\mathrm{F})$ & $1.0 \pm 0.2$ & $0.7 \pm 0.3$ & $0.5 \pm 0.2$ & $19.9 \pm 5.5$ & $14.4 \pm 3.2$ & - & $63.5 \pm 6.2$ \\
\hline
\end{tabular}



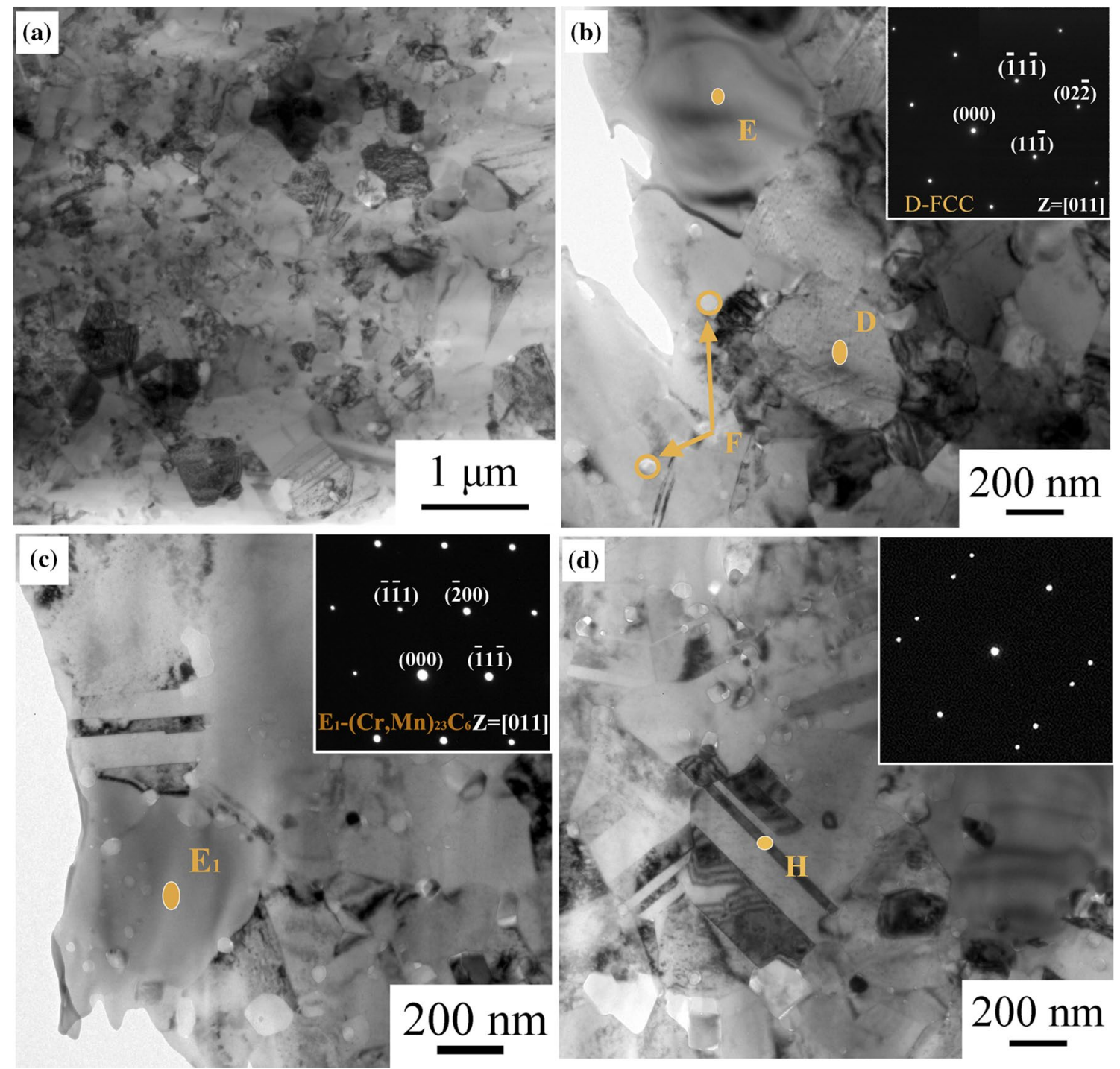

Fig. 3 Bright-field (BF) TEM images of bulk FeNiCoCrMn HEA: a low-magnified image; b high-magnified image and SAED pattern corresponding to grain D (FCC); $\mathbf{c}$ high-magnified image and SAED pattern corresponding to grain $\mathrm{E}_{1}\left((\mathrm{Cr}, \mathrm{Mn})_{23} \mathrm{C}_{6}\right)$; $\boldsymbol{d}$ nanotwinned grain $\mathrm{H}$ and its corresponding SAED pattern

Table 2 Mixing enthalpy $\left(\Delta H_{i j}^{\mathrm{mix}}, \mathrm{kJ} \mathrm{mol}^{-1}\right)$ of different atom pairs calculated by Miedemas model $[3,34]$

\begin{tabular}{lllllll}
\hline $\begin{array}{l}\text { Element (atomic radii, } \\
\text { A })\end{array}$ & $\mathrm{C}$ & $\mathrm{Fe}$ & $\mathrm{Ni}$ & $\mathrm{Co}$ & $\mathrm{Cr}$ & $\mathrm{Mn}$ \\
\hline $\mathrm{C}(0.77)$ & - & -50 & -39 & -42 & -61 & -66 \\
$\mathrm{Fe}(1.27)$ & - & - & -2 & -1 & -1 & 0 \\
$\mathrm{Ni}(1.25)$ & - & - & - & 0 & -7 & -8 \\
$\mathrm{Co}(1.26)$ & - & - & - & - & -4 & -5 \\
$\mathrm{Cr}(1.28)$ & - & - & - & - & - & 2 \\
$\mathrm{Mn}(1.29)$ & - & - & - & - & - & - \\
\hline
\end{tabular}

negligible. The value of mixing enthalpy for atom pairs of these elements almost approaches to $0 \mathrm{~kJ} \mathrm{~mol}^{-1}$, and the maximum mixing enthalpy is $-8 \mathrm{~kJ} \mathrm{~mol}^{-1}$. It suggests that $\mathrm{Fe}, \mathrm{Ni}, \mathrm{Co}, \mathrm{Cr}$ and $\mathrm{Mn}$ have remarkably high mutual solubility to each other. In other words, solid-solution phases can be formed between these elements. Therefore, it is reasonable that solid-solution phase with FCC structure could be formed in $\mathrm{FeNiCoCr}$ and $\mathrm{FeNiCoCrMn}$ 
HEAs, respectively, which is in accordance with the EDS/ TEM results and the previous studies [13, 23]. Note that the mixing enthalpy of atom pairs between $\mathrm{Cr}$ and $\mathrm{C}$ is $-61 \mathrm{~kJ} \mathrm{~mol}^{-1}$. Such an extremely negative mixing enthalpy of $\mathrm{Cr}$ and $\mathrm{C}$ in $\mathrm{FeNiCoCr}$ alloy indicates a great tendency to yield intermetallic compounds. According to the Ref. [35], there are three kinds of Cr-carbides, i.e., $\mathrm{Cr}_{23} \mathrm{C}_{6}, \mathrm{Cr}_{7} \mathrm{C}_{3}$ and $\mathrm{Cr}_{3} \mathrm{C}_{2}$, and the Gibbs energies are all negative for generating them even at ambient temperature. In this connection, any kind of $\mathrm{Cr}$-carbides are likely to yield in the present alloys, and their stability is determined by the content of carbon. However, note that since no carbon/oxygen was added deliberately, the formation of carbides and oxides indicates the presence of carbon and oxygen source in the milling medium or raw elemental powders. In the present study, it is reasonable to postulate that some ethanol which acts as carbon source was left over in the 50-h milled powder following drying treatment, and chromium would react with any carbon generated from ethanol decomposition when the 50-h milled powders were subjected to spark plasma sintering under high temperature. Therefore, the content of carbon was very limited in the two alloys. According to the Cr-C phase diagram [36], the relatively low content of carbon favors the formation of $\mathrm{Cr}_{23} \mathrm{C}_{6}$ in the alloys. It is worth noting that, according to Table 2, the mixing enthalpy of atom pairs between $\mathrm{Mn}$ and $\mathrm{C}$ is $-66 \mathrm{~kJ} \mathrm{~mol}^{-1}$, which is similar to that between $\mathrm{Cr}$ and $\mathrm{C}$. This reveals that $\mathrm{Mn}$ has a high solubility in the type $(\mathrm{Cr}, \mathrm{Mn})_{23} \mathrm{C}_{6}$ phase, leading to a small lattice expansion of $\mathrm{Cr}_{23} \mathrm{C}_{6}$ phase as mentioned above. Therefore, the formation of $(\mathrm{Cr}, \mathrm{Mn})_{23} \mathrm{C}_{6}$ phase is reasonable in the bulk FeNiCoCrMn alloy. In addition, the nanosized $\mathrm{Cr}_{2} \mathrm{O}_{3}$ phase is readily formed in the $\mathrm{FeNiCoCr}$ alloy while $\mathrm{MnCr}_{2} \mathrm{O}_{4}$ phase tends to yield in the FeNiCoCrMn alloy. Since Cr-oxides and Mn-oxides both having the most negative Gibbs energies to be generated among the constituent elements [37]. The oxygen atoms in the reaction could be derived from the oxidized surface of the raw elemental powders, such as the dense oxide film on the surface of nickel and/or from the low content of oxygen in environment and PCA (ethanol).

Figure 4 shows the statistical grain diameter distribution histogram obtained by measuring hundreds of grains using the ImageJ image analyzer. It can be clearly seen that the grain size of the bulk $\mathrm{FeNiCoCr}$ alloy ranges from several tens nanometers to $1000 \mathrm{~nm}$ with an average grain diameter of $416 \mathrm{~nm}$. While the grain size of the bulk FeNiCoCrMn alloy ranges from several hundred nanometers to $1000 \mathrm{~nm}$ with an average grain diameter of $546 \mathrm{~nm}$. In fact, in the same processing route, the grains of the quinary FeNiCoCrMn are evidently coarser than those of the quaternary $\mathrm{FeNiCoCr}$, against the hypothesis that increased configurational entropy would slow down diffusion rate of HEAs. Actually, the coarsening phenomenon is mainly attributed to a lower melting temperature of the quinary FeNiCoCrMn HEA. With the addition of a lower melting point element $\mathrm{Mn}$, the melting temperature decreases from $1444{ }^{\circ} \mathrm{C}$ ( $\mathrm{FeNiCoCr}$ alloy) to $1334^{\circ} \mathrm{C}$ (FeNiCoCrMn alloy) [38]. It suggests that the equilibrium vacancy concentration would be higher in the quinary $\mathrm{FeNiCoCrMn}$ at the same sintering temperature, resulting in a higher intrinsic diffusion coefficient as compared to that of the quaternary FeNiCoCr. Thus, the grain growth of FeNiCo$\mathrm{CrMn}$ is more pronounced than that of $\mathrm{FeNiCoCr}$ during SPS. In addition, grain size and volume fraction of $\mathrm{Cr}_{2} \mathrm{O}_{3}$ phase are estimated to be $\sim 28 \mathrm{~nm}$ and $\sim 4$ vol. $\%$ in the bulk $\mathrm{FeNiCoCr}$ alloy, respectively, whereas those values for $\mathrm{MnCr}_{2} \mathrm{O}_{4}$ phase in FeNiCoCrMn alloy are $\sim 36 \mathrm{~nm}$ and $\sim 5$ vol.\%, respectively. Grain size and volume fraction of $M_{23} \mathrm{C}_{6}$ in the $\mathrm{FeNiCoCr}$ alloy are estimated to be $380 \mathrm{~nm}$ and $\sim 5$ vol. $\%$, whereas those values are $\sim 520 \mathrm{~nm}$ and $\sim 6$ vol.\% in the FeNiCoCrMn alloy.
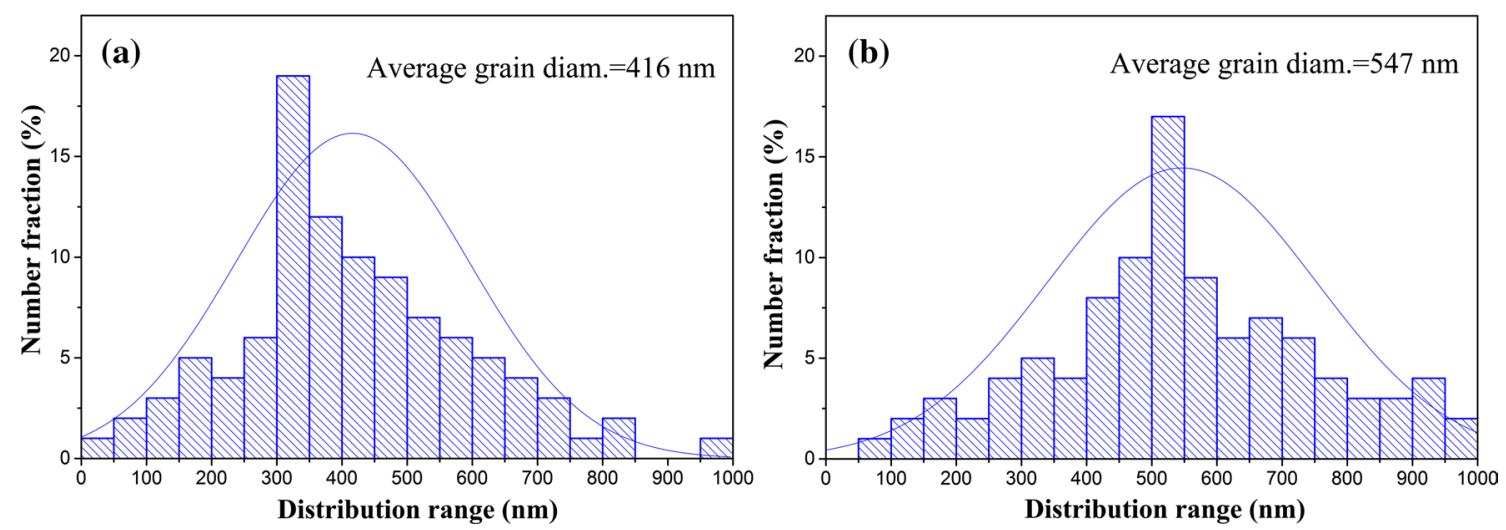

Fig. 4 Statistical grain diameter distribution histogram: a grain size distribution histogram of bulk FeNiCoCr with an average grain diameter of $416 \mathrm{~nm}$; b grain size distribution histogram of bulk FeNiCoCrMn with an average grain diameter of $547 \mathrm{~nm}$ 


\subsection{Mechanical Properties}

The representative compression engineering stress-strain curves of bulk FeNiCoCr and FeNiCoCrMn HEAs at room temperature are presented in Fig. 5. It can be seen that these two HEAs fabricated in the present work have exceptional compressive performance. The compressive yield strength and strain at failure of the $\mathrm{FeNiCoCr}$ alloy are $1525 \mathrm{MPa}$ and $24.4 \%$, respectively. The average microhardness of the bulk FeNiCoCr HEA is measured to be $465 \mathrm{HV}$. However, the bulk FeNiCoCrMn displays a lower mechanical performance compared to the bulk FeNiCoCr alloy. With the addition of $\mathrm{Mn}$, the yield strength decreases from 1525 to $1329 \mathrm{MPa}$, and strain-tofailure decreases from 24.4 to $21.9 \%$, respectively. The Vickers hardness of FeNiCoCrMn exhibits a decrement of $12.5 \%$ as compared to that of FeNiCoCr. Table 3 summarizes mechanical properties of the two bulk FeNiCoCr and FeNiCoCrMn HEAs prepared by various methods. Among the listed HEAs, though the as-cast FeNiCoCr alloy displays the highest value of strain-to-failure, the yield strength is only $140 \mathrm{MPa}$. It is evident that although the strain-to-failure of SPSed HEAs is inferior to that of the as-cast HEAs, those yield strength and compressive

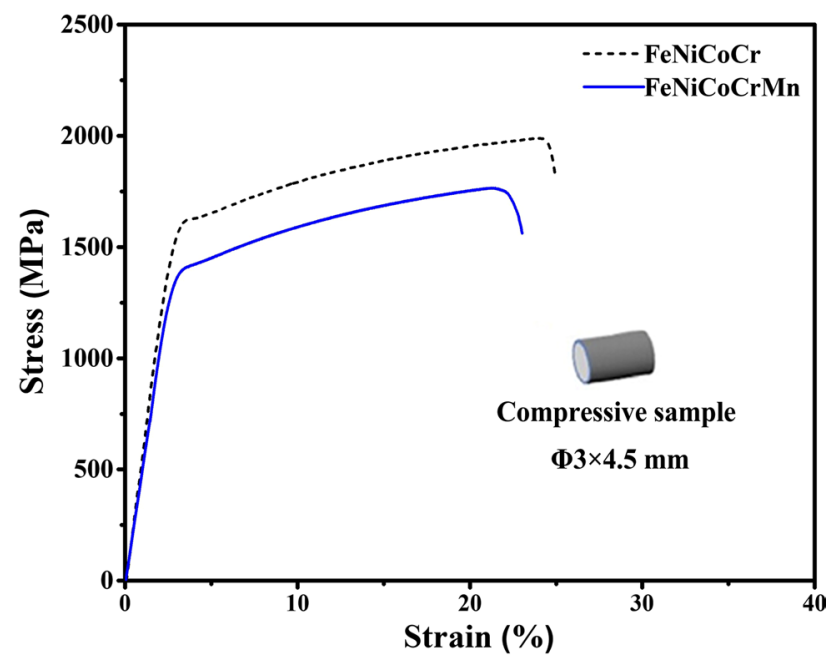

Fig. 5 Representative engineering stress-strain curves of bulk FeNiCoCr and $\mathrm{FeNiCoCrMn} \mathrm{HEAs} \mathrm{under} \mathrm{compression} \mathrm{at} \mathrm{room} \mathrm{tempera-}$ ture

Table 3 Mechanical properties of $\mathrm{FeNiCoCr}$ and $\mathrm{FeNiCoCrMn}$ HEAs prepared by various methods at room temperature

\begin{tabular}{lllllll}
\hline Alloys & Process & $\sigma_{0.2}(\mathrm{MPa})$ & $\sigma_{\max }(\mathrm{MPa})$ & $\varepsilon_{f}(\%)$ & Hardness $\left(\mathrm{H}_{\mathrm{V}}\right)$ & References \\
\hline FeNiCoCr & MA and SPS & 1525 & 1987 & 24.4 & 465 & This work \\
FeNiCoCrMn & MA and SPS & 1329 & 1761 & 21.9 & 407 & This work \\
FeNiCoCr & MA and SPS & 657 & - & $>50$ & - & {$[39]$} \\
FeNiCoCrMn & MA and SPS & $700^{\mathrm{a}}$ & $762^{\mathrm{a}}$ & $9.8^{\mathrm{a}}$ & 314 & {$[40]$} \\
FeNiCoCr & Arc-melting and casting & $140^{\mathrm{a}}$ & $488^{\mathrm{a}}$ & $83^{\mathrm{a}}$ & 160 & {$[17]$} \\
FeNiCoCrMn & Arc-melting and casting & $215^{\mathrm{a}}$ & $491^{\mathrm{a}}$ & $71^{\mathrm{a}}$ & 170 & {$[17]$}
\end{tabular}

${ }^{\mathrm{a}}$ The data were from tensile properties of FeNiCoCr and FeNiCoCrMn HEAs. Note that the tensile yield strength is almost equivalent to compressive yield strength in alloys 
retained effectively. At this balance, the limiting grain size $\left(d_{1}\right)$ with fine oxide particles is calculated by [43]:

$d_{1}=\frac{4 r}{3 f}$,

where $f$ and $r$ are the volume fraction and radius of oxide precipitates, respectively. Accordingly, the calculated results of limiting grain size are $\sim 933 \mathrm{~nm}$ and $\sim 960 \mathrm{~nm}$ for the bulk $\mathrm{FeNiCoCr}$ and $\mathrm{FeNiCoCrMn}$ alloys, respectively. In fact, the average grain size of $\mathrm{FeNiCoCr}(416 \mathrm{~nm})$ and $\mathrm{FeNiCoCrMn}$ $(546 \mathrm{~nm})$ alloys is significantly smaller than the calculated results. In other words, in addition to pinning effect of oxides, the presence of $\mathrm{Cr}_{23} \mathrm{C}_{6} /(\mathrm{Cr}, \mathrm{Mn})_{23} \mathrm{C}_{6}$ carbides also plays an important roles in controlling the grain size. In a dual-phase mixture, the growth of one phase will inescapably influence the other phase due to their simultaneous process and mutual topological constraint [44]. Specifically, the final grain size would be determined by the phase with a slower grain growth rate. In the present work, the carbides are surrounded by the FCC grains, and therefore the grain growth of the carbides depends on the diffusion of $\mathrm{Cr}$ and $\mathrm{C}$ atoms through FCC matrix or along grain boundaries. This long range diffusion of $\mathrm{Cr}$ and $\mathrm{C}$ atoms together with sluggish diffusion of FCC matrix degenerate the growth/coarsening of the two phases (the FCC phase and carbides). As such, the formation carbide and oxide contaminants can suppress the grain growth, thereby achieving an enhanced grain-boundary strengthening.

The contribution of grain-boundary strengthening can be well estimated using classical Hall-Petch equation [45, 46]

$\sigma_{0.2}=\sigma_{0}+k_{y} D^{-\frac{1}{2}}$

where $\sigma_{0.2}$ is the yield stress. $\sigma_{0}$ and $k_{y}$ represent friction stress and Hall-Petch coefficient, respectively, and their values are in Table 4. Based on Eq. (5), the increment of yield strength caused by grain-boundary strengthening $\left(\Delta \sigma_{\mathrm{gb}}\right)$ can be expressed as follows [47],

$\Delta \sigma_{\mathrm{gb}}=k_{y}\left(D^{-1 / 2}-D_{\text {cast }}^{-1 / 2}\right)$,

where $D$ represents the average diameter of FCC grains in the present study $(0.416 \mu \mathrm{m}$ for $\mathrm{FeNiCoCr}$ and $0.546 \mu \mathrm{m}$ for
FeNiCoCrMn). $D_{\text {cast }}$ is the average diameter of FCC grains of as-cast alloys $(\sim 24 \mu \mathrm{m}$ for $\mathrm{FeNiCoCr}$ and $\sim 50 \mu \mathrm{m}$ for FeNiCoCrMn [49]). Accordingly, the increment of yield strength caused by grain-boundary strengthening $\left(\Delta \sigma_{\mathrm{gb}}\right)$ is $1155 \mathrm{MPa}$ and $600 \mathrm{MPa}$ for the present $\mathrm{FeNiCoCr}$ and $\mathrm{FeN}$ iCoCrMn HEAs, respectively, as compared to their as-cast counterparts. In addition, the nanosized oxides distributed in the matrix can impede dislocation movement by Orowan strengthening mechanism, which can be expressed as follows [47],

$\Delta \sigma_{\mathrm{Or}}=0.538\left(\frac{f^{1 / 2} G b}{d}\right)\left(\ln \frac{d}{2 b}\right)$,

where the physical meaning and values of $G$ and $b$ are depicted in Table 4. $d$ and $f$ represent the particle size and volume fraction of oxides, respectively. The calculated values of dispersion strengthening of oxides $\left(\Delta \sigma_{\mathrm{Or}}\right)$ are $318 \mathrm{MPa}$ and $293 \mathrm{MPa}$ for the $\mathrm{FeNiCoCr}$ and $\mathrm{FeNiCo}-$ CrMn alloys, respectively. The above estimated values for the strengthening mechanisms reveal that grain-boundary strengthening is the dominant mechanism for the two FeN$\mathrm{iCoCr}$ and $\mathrm{FeNiCoCrMn} \mathrm{HEAs} \mathrm{in} \mathrm{the} \mathrm{present} \mathrm{study.}$

The FeNiCoCrMn HEA displays a lower yield strength and plasticity compared to the FeNiCoCr HEA. The primary reason for this phenomenon is the smaller grain size of the primary FCC phase (Fig. 4), leading to an enhanced grain-boundary strengthening in the $\mathrm{FeNiCoCr}$ alloy. In addition, the coarser and higher volume fractions of carbides and oxides in the bulk FeNiCoCrMn HEA result in lower plasticity.

\section{Conclusions}

Nearly full-dense bulk FeNiCoCr and FeNiCoCrMn HEAs were successfully realized through MA and SPS. Following MA, a primary FCC phase with the coexistence of BCC phase formed in both of the FeNiCoCr and FeNiCoCrMn HEAs. Phase transformation occurred during SPS in both alloys, resulting in the metastable $\mathrm{BCC}$ phase transformed into a more stable FCC phase. The bulk FeNiCoCr HEA presents
Table 4 Physical meaning and values of parameters used for the $\mathrm{FeNiCoCr}$ and FeNiCoCrMn HEAs in estimating strengthening mechanisms

\begin{tabular}{llllll}
\hline Alloys & Parameters & Physical meaning & Value & Unit & References \\
\hline FeNiCoCr & $\sigma_{0}$ & Friction stress & 175 & $\mathrm{MPa}$ & {$[48]$} \\
& $k_{y}$ & Hall-Petch coefficient & 855 & ${\mathrm{MPa} \mu \mathrm{m}^{-0.5}}$ & {$[49]$} \\
& $G$ & Shear modulus & 82 & $\mathrm{GPa}$ & {$[49]$} \\
& $b$ & Magnitude of the Burgers vector & 0.251 & $\mathrm{~nm}$ & {$[48]$} \\
FeNiCoCrMn & $\sigma_{0}$ & Friction stress & 125 & $\mathrm{MPa}$ & {$[45]$} \\
& $k_{y}$ & Hall-Petch coefficient & 494 & $\mathrm{MPa} \mu \mathrm{m}^{-0.5}$ & {$[49]$} \\
& $G$ & Shear modulus & 80 & $\mathrm{GPa}$ & {$[49]$} \\
& $b$ & Magnitude of the Burgers vector & 0.258 & $\mathrm{~nm}$ & {$[41]$} \\
\hline
\end{tabular}


$\mathrm{Ni}-\mathrm{Co}$-rich and $\mathrm{Cr}$-depleted FCC matrix with a small amount of $\mathrm{Cr}_{23} \mathrm{C}_{6}$ and $\mathrm{Cr}_{2} \mathrm{O}_{3}$ contaminants, while the bulk FeNiCoCrMn HEA exhibits Fe-Ni-rich and $\mathrm{Cr}$-depleted FCC matrix with some $(\mathrm{Cr}, \mathrm{Mn})_{23} \mathrm{C}_{6}$ and $\mathrm{MnCr}_{2} \mathrm{O}_{4}$ contaminants. The average grain diameter increases from 416 to $546 \mathrm{~nm}$ when $\mathrm{Mn}$ was added to the quaternary $\mathrm{FeNiCoCr} \mathrm{HEA}$, which is mainly attributed to a higher intrinsic diffusion coefficient of bulk FeNiCoCrMn at the same sintering temperature.

Both HEAs possess an attractive combination of strength-ductility in the present work. The yield strength and strain-to-failure of the FeNiCoCr alloy are $1525 \mathrm{MPa}$ and $24.4 \%$, respectively, whereas these values for the FeNiCoCrMn alloy exhibit decrement of $12.8 \%$ and $10.2 \%$, respectively. Clearly, the smaller grain size of the primary FCC phase in the FeNiCoCr alloy is mainly responsible for the better mechanical performance.

Acknowledgements This work was supported by the Opening Project of Guangdong Key Laboratory for Advanced Metallic Materials Processing, South China University of Technology (GJ201601).

\section{References}

[1] J.W. Yeh, S.K. Chen, S.J. Lin, J.Y. Gan, T.S. Chin, T.T. Shun, C.H. Tsau, S.Y. Chang, Adv. Eng. Mater. 6, 299 (2004)

[2] W.R. Zhang, P.K. Liaw, Y. Zhang, Sci. China Mater. 61, 2 (2018)

[3] D.B. Miracle, O.N. Senkov, Acta Mater. 122, 448 (2017)

[4] L. Moravcikova-Gouvea, I. Moravcik, M. Omasta, J. Vesely, J. Cizek, P. Minarik, J. Cupera, A. Zadera, V. Jan, I. Dlouhy, Mater. Charact. 159, 110046 (2020)

[5] C.G. Schön, M.A. Tunes, R. Arróyave, J. Ågren, CALPHAD: Comput. Coupling Phase Diagr. Thermochem. 68, 101713 (2020)

[6] Z.Q. Fu, W.P. Chen, H.M. Wen, D.L. Zhang, Z. Chen, B.L. Zheng, Y.Z. Zhou, E.J. Lavernia, Acta Mater. 107, 59 (2016)

[7] S.Y. Chen, W.D. Li, X. Xie, J. Brechtl, B.L. Chen, P.Z. Li, G.F. Zhao, F.Q. Yang, J.W. Qiao, K.A. Dahmen, P.K. Liaw, J. Alloys Compd. 752, 464 (2018)

[8] W. Kai, F.P. Cheng, F.C. Chien, Y.R. Lin, D. Chen, J.J. Kai, C.T. Liu, C.J. Wang, Corros. Sci. 158, 108093 (2019)

[9] N.A.P.K. Kumar, C. Li, K.J. Leonard, H. Bei, S.J. Zinkle, Acta Mater. 113, 230 (2016)

[10] Z. Li, S. Zhao, S.M. Alotaibi, Y. Liu, B. Wang, M.A. Meyers, Acta Mater. 151, 424 (2018)

[11] T. Zuo, M. Zhang, P.K. Liaw, Y. Zhang, Intermetallics 100, 1 (2018)

[12] B. Cantor, I.T.H. Chang, P. Knight, A.J.B. Vincent, Mater. Sci. Eng., A 375, 213 (2004)

[13] M. Vaidya, K. Guruvidyathri, B.S. Murty, J. Alloys Compd. 774, 856 (2019)

[14] M. Laurent-Brocq, A. Akhatova, L. Perrière, S. Chebini, X. Sauvage, E. Leroy, Y. Champion, Acta Mater. 88, 355 (2015)

[15] B. Gludovatz, A. Hohenwarter, D. Catoor, E.H. Chang, E.P. George, R.O. Ritchie, Science 345, 1153 (2014)

[16] M. Naeem, H.Y. He, F. Zhang, H.L. Huang, S. Harjo, T. Kawasaki, B. Wang, S. Lan, Z.D. Wu, F. Wang, Y. Wu, Z.P. Lu, Z.W. Zhang, C.T. Liu, X.L. Wang, Sci. Adv. 6, 4002 (2020)
[17] G.A. Salishchev, M.A. Tikhonovsky, D.G. Shaysultanov, N.D. Stepanov, A.V. Kuznetsov, I.V. Kolodiy, A.S. Tortika, O.N. Senkov, J. Alloys Compd. 591, 11 (2014)

[18] B.S. Murty, S. Ranganathan, Int. Mater. Rev. 43, 101 (1998)

[19] A.S. Sharma, S. Yadav, K. Biswas, B. Basu, Mater. Sci. Eng., R 131, 1 (2018)

[20] Z.F. Jiang, W.P. Chen, Z.B. Xia, W. Xiong, Z.Q. Fu, Intermetallics 108, 45 (2019)

[21] Y.H. Guo, M.Y. Li, P. Li, C.G. Chen, Q. Zhan, Y.Q. Chang, Y.W. Zhang, J. Alloys Compd. 820, 153104 (2020)

[22] P. Sathiyamoorthi, J. Basu, S. Kashyap, K.G. Pradeep, R.S. Kottada, Mater. Des. 134, 426 (2017)

[23] M. Vaidya, A. Anupam, J.V. Bharadwaj, C. Srivastava, B.S. Murty, J. Alloys Compd. 791, 1114 (2019)

[24] Z.Q. Fu, W.P. Chen, S.C. Fang, X.M. Li, Mater. Sci. Eng., A 597, 204 (2014)

[25] Y. Zhang, T.T. Zuo, Z. Tang, M.C. Gao, K.A. Dahmen, P.K. Liaw, Z.P. Lu, Prog. Mater Sci. 61, 1 (2014)

[26] K.B. Zhang, Z.Y. Fu, J.Y. Zhang, J. Shi, W.M. Wang, H. Wang, Y.C. Wang, Q.J. Zhang, J. Alloys Compd. 485, L31 (2009)

[27] S. Praveen, B.S. Murty, R.S. Kottada, JOM 65, 1797 (2013)

[28] T.T. Shun, Y.C. Du, J. Alloys Compd. 478, 269 (2009)

[29] S.C. Fang, W.P. Chen, Z.Q. Fu, Mater. Des. 54, 973 (2014)

[30] J.Y. Pang, T. Xiong, X. Wei, Z.W. Zhu, B. Zhang, Y.T. Zhou, X.H. Shao, Q.Q. Jin, S.J. Zheng, X.L. Ma, Materialia 6, 100275 (2019)

[31] F. Otto, A. Dlouhý, C. Somsen, H. Bei, G. Eggeler, E.P. George, Acta Mater. 61, 5743 (2013)

[32] A.J. Zaddach, C. Niu, C.C. Koch, D.L. Irving, JOM 65, 1780 (2013)

[33] Z.Q. Fu, W.P. Chen, S.C. Fang, D.Y. Zhang, H.Q. Xiao, D.Z. Zhu, J. Alloys Compd. 553, 316 (2013)

[34] A. Takeuchi, A. Inoue, Mater. Trans. 46, 2817 (2005)

[35] S.R. Shatynski, Oxid. Met. 13, 105 (1979)

[36] J.O. Andersson, CALPHAD: Comput. Coupling Phase Diagr. Thermochem. 11, 271 (1987)

[37] W. Kai, C.C. Li, F.P. Cheng, K.P. Chu, R.T. Huang, L.W. Tsay, J.J. Kai, Corros. Sci. 108, 209 (2016)

[38] M. Vaidya, S. Trubel, B.S. Murty, G. Wilde, S.V. Divinski, J. Alloys Compd. 688, 994 (2016)

[39] B. Jia, X.J. Liu, H. Wang, Y. Wu, Z.P. Lu, Sci. China: Technol. Sci. 61, 179 (2018)

[40] Y. Liu, J.S. Wang, Q.H. Fang, B. Liu, Y. Wu, S.Q. Chen, Intermetallics 68, 16 (2016)

[41] M.V. Klimova, D.G. Shaysultanov, S.V. Zherebtsov, N.D. Stepanov, Mater. Sci. Eng., A 748, 228 (2019)

[42] M. Vaidya, K.G. Pradeep, B.S. Murty, G. Wilde, S.V. Divinski, Sci. Rep. 7, 12293 (2017)

[43] S. Praveen, J. Basu, S. Kashyap, R.S. Kottada, J. Alloys Compd. 662, 361 (2016)

[44] K.B. Alexander, P.F. Becher, S.B. Waters, A. Bleier, J. Am. Ceram. Soc. 77, 939 (1994)

[45] N.D. Stepanov, D.G. Shaysultanov, R.S. Chernichenko, D.M. Ikornikov, V.N. Sanin, Mater. Sci. Eng., A 728, 54 (2018)

[46] N.D. Stepanov, D.G. Shaysultanov, R.S. Chernichenko, M.A. Tikhonovsky, S.V. Zherebtsov, J. Alloys Compd. 770, 194 (2019)

[47] J.A. Peng, Z.Y. Li, L.M. Fu, X.B. Ji, Z.R. Pang, A.D. Shan, J. Alloys Compd. 803, 491 (2019)

[48] B. Liu, J.S. Wang, Y. Liu, Q.H. Fang, Y. Wu, S.Q. Chen, C.T. Liu, Intermetallics 75, 25 (2016)

[49] Z.G. Wu, Y.F. Gao, H.B. Bei, Acta Mater. 120, 108 (2016) 